\title{
Effect of Rocker Bar Ankle Foot Orthosis on Functional Mobility in Post-Stroke Hemiplegic Patients: Timed Up and Go and Gait Speed Assessments
}

\author{
Farzad Farmani ${ }^{1,2}$, Mohammad Ali Mohseni-Bandpei ${ }^{3,4,5^{*}}$, Mahmood Bahramizadeh², Gholamreza Aminian², Mohammad Reza Nikoo ${ }^{1}$ \\ Mohammad Sadeghi-Goghari ${ }^{6}$ \\ 1. Department of Orthotics \& Prosthetics, School of Rehabilitation Sciences, Hamedan University of Medical Sciences, Hamadan, Iran. \\ 2. Department of Orthotics \& Prosthetics, University of Social Welfare and Rehabilitation Sciences, Tehran, Iran. \\ 3. Iranian Research Center on Aging, University of Social Welfare and Rehabilitation Sciences, Tehran, Iran. \\ 4. Department of Physiotherapy, University of Social Welfare and Rehabilitation Sciences, Tehran, Iran. \\ 5. Institute of Physical Therapy, Faculty of Allied Health Sciences, University of Lahore, Lahore, Pakistan \\ 6. Department of Physiotherapy, Faculty of Paramedical Sciences, Kerman University of Medical Sciences, Kerman, Iran.
}

Citation: Farmani F, Mohseni-Bandpei MA, Bahramizadeh M, Aminian Gh, Nikoo MR, Sadeghi-Goghari M. Effect of rocker bar ankle foo orthosis on functional mobility in post-stroke hemiplegic patients: Timed up and go and gait speed assessments. Iranian Rehabilitation Journal. 2016; 14(1):31-34. http://dx.crossref.org/10.15412/J.IRJ.08140105

doI ${ }^{s}$ : http://dx.crossref.org/10.15412/J.IRJ.08140105

Article info:

Received: 09 Sep. 2015

Accepted: 17 Jan. 2016

\section{Keywords:}

Rocker bar ankle foot orthosis, Functional mobility,

Hemiplegic patients

\section{ABSTRACT}

Objectives: Ankle Foot Orthoses (AFOs) are widely utilized to improve walking ability in hemiplegic patients. The present study aimed to evaluate the effect of Rocker bar Ankle Foot Orthosis (RAFO) on functional mobility in post-stroke hemiplegic patients.

Methods: Fifteen hemiplegic patients (men and women) who were at least 6-months poststroke and able to walk without an assistive device for at least 10 meters voluntarily participated in this study. The patients were examined for three conditions: shoes only, with SAFO and with RAFO. Their functional mobility was evaluated through 10-meter walk test and Timed Up and Go (TUG) test. In addition, paired t-test was used to analyze the obtained data.

Results: When the patients used RAFO, their gait speed significantly increased $(\mathrm{P}<0.05)$ Moreover, the time of performing TUG test experienced a significant decrease using RAFO compared with utilizing shoe only $(\mathrm{P}<0.05)$.

Discussion: RAFO led to a significant improvement in functional mobility in hemiplegic patients post stroke. This may be due to the positive effect of rocker modification on improving push off and transferring weight during the stance phase of gait.

\section{Introduction}

emiplegia secondary to stroke contributes to problems associated with standing and walking. Hemiplegic patients suffer from poor balance, slow walking, and weak muscles, and their lower limb is often accompanied with an equinovarus deformity in ankle-foot complex [1-3]. Ankle Foot Orthoses (AFOs) are widely prescribed for patients with hemiplegia to improve balance and facilitate gait. Various studies have reported the positive effects of AFOs on the walking ability in hemiplegic pa-

\section{* Corresponding Author:}

Mohammad Ali Mohseni-Bandpei, PhD, PT

Address: Iranian Research Center on Aging, University of Social Welfare and Rehabilitation Sciences, Tehran, Iran

Tel: +98 (21) 22180137

E-mail: mohseni_bandpei@yahoo.com 
tients $[4,5]$. AFOs also help patients in both stance and swing phases of gait by stabilizing ankle-foot complex and preventing abrupt foot drop $[6,7]$.

For hemiplegic patients, gait speed is a key factor that can directly affect their daily activities. Therefore, enhancing walking speed is an important goal regarding prescribing AFO for individuals with hemiplegia [8]. Preferred walking speed in healthy subjects is $1.18 \mathrm{~m} / \mathrm{s}$ for men above 64 years and $0.96 \mathrm{~m} / \mathrm{s}$ for women above 60 years. Although Solid AFO (SAFO) enhances walking speed in hemiplegic patients, the acquired speed is far less than that of the healthy subjects [9]. Thus, some efforts have been done to increase gait velocity with common SAFO [7, 10-12]. Considering the positive effect of rocker bar modification added to orthoses on walking velocity reported in previous studies [13-15], we hypothesized that adding rocker bar to a SAFO could potentially improve walking speed in hemiplegic patients. Timed Up and Go test (TUG) is a valid and reliable test, which could evaluate several tasks concurrently, for examining the acquired functional ability in patients [16-18]. Hence, we used TUG to investigate the effectiveness of Rocker bar AFO (RAFO) on functional mobility in hemiplegic patients, in addition to using the 10-meter walk test to investigate gait speed [19-21]. Thus, the aim of this study was to evaluate the effect of RAFO on functional mobility in post-stroke hemiplegic patients.

\section{Methods}

\section{Patients}

Fifteen post-stroke hemiplegic patients including ten men and five women voluntarily participated in this study. Inclusion criteria were as follows: age between 40 to 70 years, having the ability to walk without an assistive device for at least ten meters, and having a maximum spasticity of 3 according to the Modified Ashworth Scale. Exclusion criteria were having a deformity in spine or lower limbs (except for equinovarus in ankle join in paretic side), having a history of surgery in the spine or lower limbs, and having severe cardiovascular, respiratory or cognitive problems. Table 1 indicates the demographic characteristics of the patients.

\section{Orthosis}

Patients were provided with a custom-made SAFO and RAFO. In order to provide RAFO, SAFO was modified with a rocker sole added below the footplate. The rocker modification had a height of $2 \mathrm{~cm}$. The rocker bar started slightly proximal to metatarsal heads, and its angle was
15 degrees. Orthoses were prepared and fitted to the patients' limb by an expert orthotist.

All the patients were examined in three conditions including shoe only, with SAFO and with RAFO in random sequences. Moreover, all the participants used the same shoes.

\section{Measurements}

- Preferred Gait Speed (PGS): The participants were instructed to walk for 10 meters at their self-selected speed. The time of doing task was recorded and divided into passed distance to obtain gait speed $(\mathrm{m} / \mathrm{s})$.

- TUG test: The patients were asked to stand up from a standard chair, walk for 3 meters, turn, walk back to the chair, and sit down again. The time of task was recorded in seconds.

All the measurements were done three times, and the average data was considered for final analysis. Means and standard deviation of the performed measurements were recorded. All participants signed informed consent prior to performing the tests. Furthermore, the current study received ethical approval from the Medical Ethics Board at the University of Social Welfare and Rehabilitation Sciences.

\section{Data analysis}

We used repeated measures analysis of variance test (ANOVA) to analyze the differences among measurements. Tukey Honestly Significance Difference (THSD) post hoc tests were used to identify the specific difference between two groups. We utilized SPSS statistical software version 16.0 (SPSS Inc., Chicago, IL) to analyze obtained data. The level of $\alpha=0.05$ was considered statistically significant.

\section{Results}

Table 2 shows the data regarding functional test parameters including Preferred Walking Speed and TUG test in three conditions: shoes only, with SAFO and with RAFO. There were significant differences between shoes only condition and using SAFO or RAFO $(\mathrm{P}<0.05)$. Both SAFO and RAFO led to faster gait speed and less timed TUG test compared with shoes only condition. Moreover, RAFO significantly resulted in higher gait speed and less time in doing TUG compared to SAFO $(\mathrm{P}<0.05)$.

\section{Discussion}

The aim of the present study was to investigate the effect of RAFO on functional mobility parameters in- 
Table 1. Demographic characteristics of the patients $(\mathrm{N}=15)$.

\begin{tabular}{ccccc}
\hline Gender & $\begin{array}{c}\text { Age mean } \\
\text { (year) }(\text { mean } \pm \text { SD })\end{array}$ & $\begin{array}{c}\text { Weight } \\
(\mathbf{k g})(\mathbf{m e a n} \pm \text { SD })\end{array}$ & Paretic side & $\begin{array}{c}\text { Months after stroke } \\
\text { (mean } \pm \text { SD) }\end{array}$ \\
\hline Male: 10 & $54.23 \pm 9.65$ & $66.95 \pm 11$ & Left: 11 & $22.13 \pm 14$ \\
Female: 5 & & Right: 4 & \\
\hline
\end{tabular}

Iranian Rehabilitation Journa

Table 2. The Mean \pm SD of functional mobility parameters in three conditions: Shoes only, with SAFO and with RAFO.

\begin{tabular}{ccccccc}
\hline & Shoes only & SAFO & RAFO & P1 & P2 & P3 \\
\hline PGS (m/s) & $0.36 \pm 0.11$ & $0.54 \pm 0.26$ & $0.73 \pm 0.24$ & 0.033 & 0.018 & 0.029 \\
TUG (s) & $28.06 \pm 4.06$ & $23.18 \pm 3.55$ & $20.36 \pm 3.81$ & 0.021 & 0.006 & 0.045 \\
\hline
\end{tabular}

P1: Comparison between shoes only condition and SAFO.

Iranian Rehabilitation Journa

P2: Comparison between shoes only condition and RAFO.

P3: Comparison between SAFO and RAFO.

SAFO: Solid Ankle Foot Orthosis, RAFO: Rocker bar Ankle Foot Orthosis, PGS: Preferred Gait Speed, TUG: Timed Up and Go, m: meter, s: second, $\mathrm{P}<0.05$.

cluding gait speed and TUG in post-stroke hemiplegic patients compared with SAFO. The results of this study showed that SAFO led to significant improvement in functional mobility. This was consistent with previous research that showed SAFO increased gait speed and decreased TUG time compared to shoes only condition. In addition, RAFO contributed to further more improved functional mobility in patients. On comparing RAFO to SAFO, there were significant differences in both gait speed and the time of performing TUG test.

According to Perry and Burnfield [22], the normal function of the foot consists of three sequential rockers: heel rocker (first rocker), ankle rocker (second rocker), and third rocker (forefoot rocker). Research has indicated that SAFO enhances gait speed by improving first and second rockers while it has no positive effect on the third rocker [23-25]. In some cases, it has been shown that $\mathrm{AFO}$ disturbs forefoot rocker in late stance $[25,26]$.

On the other hand, it is proved that rocker bar could improve weight progression on foot and change the kinetic and kinematic functions of the ankle-foot complex [15, 27]. Therefore, it has been suggested to be used in cases in which ankle-foot complex has been immobilized such as utilizing orthoses [15]. It seems that in the current study, modifying AFO in the forefoot part resulted in improving forefoot rocker and therefore, push-off and body weight transferring in late stance. This finding was consistent with previous research, which showed that rocker modification changes the biomechanical function of the foot and ankle during walking $[14,15]$. Similarly, it was recorded that lower limb orthoses modified with forefoot rocker increased gait speed in other neurologically disabled patients [13]. However, the precise mechanism of this improvement should be evaluated in future studies.

\section{Conclusion}

The finding of this study suggests that RAFO could potentially improve gait ability compared to SAFO or shoes only condition in post-stroke hemiplegic patients. One limitation of the present study was the lack of investigation of the kinematic and kinetic characteristics of the participants' gait that is highly suggested to be done in the future. In addition, future studies should also evaluate the RAFO effectiveness. The short sample size was another limitation of the current study. Examining the effects of RAFO on hemiplegic gait in a study with a larger sample size could further prove the results obtained in this study.

\section{Acknowledgements}

The article is extracted from Mr. Farzad Farmani's $\mathrm{PhD}$ thesis in the department of orthotics \& prosthetics, Hamedan University of Medical Sciences, Hamadan, Iran.

\section{Conflict of Interest}

The authors of the present study report no conflict of interest. 


\section{References}

[1] Thijssen DH, Paulus R, van Uden CJ, Kooloos JG, Hopman MT. Decreased energy cost and improved gait pattern using a new orthosis in persons with long-term stroke. Archives of Physical Medicine and Rehabilitation. 2007; 88(2):181-86.

[2] Wang RY, Lin PY, Lee CC, Yang YR. Gait and balance performance improvements attributable to ankle-foot orthosis in subjects with hemiparesis. American Journal of Physical Medicine \& Rehabilitation. 2007; 86(7):556-62.

[3] Farmani F, Mohseni Bandpei MA, Bahramizadeh $M$, Aminian G, Nikoo MR, Sadeghi-goghari M. The effect of different shoes on functional mobility and energy expenditure in post-stroke hemiplegic patients using ankle-foot orthosis. Prosthetetics and Orthotics International. 2015. doi: $10.1177 / 0309364615592704$

[4] Tyson SF, Sadeghi-Demneh E, Nester CJ. A systematic review and meta-analysis of the effect of an ankle-foot orthosis on gait biomechanics after stroke. Clinical Rehabilitation. 2013; 27(10):879-91.

[5] Tyson SF, Kent RM. Effects of an ankle-foot orthosis on balance and walking after stroke: a systematic review and pooled meta-analysis. Archives of Physical Medicine and Rehabilitation. 2013; 94(7):1377-385.

[6] de Wit DC, Buurke JH, Nijlant JM, Ijzerman MJ, Hermens HJ. The effect of an ankle-foot orthosis on walking ability in chronic stroke patients: a randomized controlled trial. Clinical Rehabilitation. 2004; 18(5):550-57.

[7] Erel S, Uygur F, Engin Simsek I, Yakut Y. The effects of dynamic ankle-foot orthoses in chronic stroke patients at threemonth follow-up: a randomized controlled trial. Clinical Rehabilitation. 2011; 25(6):515-23.

[8] Nolan KJ, Savalia KK, Lequerica AH, Elovic EP. Objective assessment of functional ambulation in adults with hemiplegia using ankle foot orthotics after stroke. PM\&R. 2009; 1(6):524-29.

[9] Gok H, Kucukdeveci A, Altinkaynak H, Yavuzer G, Ergin S. Effects of ankle-foot orthoses on hemiparetic gait. Clinical Rehabilitation. 2003; 17(2):137-39.

[10] Danielsson A, Willen C, Sunnerhagen KS. Measurement of energy cost by the physiological cost index in walking after stroke. Archives of Physical Medicine and Rehabilitation. 2007; 88(10):1298-303.

[11] Yamamoto S, Tomokiyo N, Yasui T, Kawaguchi T. Effects of plantar flexion resistive moment generated by an anklefoot orthosis with an oil damper on the gait of stroke patients: a pilot study. Prosthetics and Orthotics International. 2013; 37(3):212-21.

[12] Yamamoto S, Hagiwara A, Mizobe T, Yokoyama O, Yasui T. Development of an ankle-foot orthosis with an oil damper. Prosthetics and orthotics International. 2005; 29(3):209-19.

[13] Arazpour M, Hutchins SW, Ahmadi Bani M, Curran S, Bahramizadeh M, Saberi H, Mardani MA. The influence of a rocker sole adaptation on gait parameters in spinal cord injury patients ambulating with the advanced reciprocating gait orthosis-a pilot study. Disability and Rehabilitation: Assistive Technology. 2015; 10(1):89-92.
[14] Farmani F, Mohseni-Bandpei MA, Bahramizadeh M Aminian G, Abdoli A, Sadeghi-Goghari M. The Influence of Rocker Bar Ankle Foot Orthosis on Gait in Patients with Chronic Hemiplegia. Journal of Stroke and Cerebrovascular Disease. Forthcoming 2016 Jun. http:/ / dx.doi.org/10.1016/j. jstrokecerebrovasdis.2016.02.021

[15] Wu WL, Rosenbaum D, Su FC. The effects of rocker sole and SACH heel on kinematics in gait. Medical Engineering \& Physics. 2004; 26(8):639-46.

[16] Deathe AB, Miller WC. The L test of functional mobility: measurement properties of a modified version of the timed "up \& go" test designed for people with lower-limb amputations. Physical Therapy. 2005; 85(7):626-35.

[17] Ng SS, Hui-Chan CW. The timed up \& go test: its reliability and association with lower-limb impairments and locomotor capacities in people with chronic stroke. Archives of Physical Medicine and Rehabilitation. 2005; 86(8):1641-647.

[18] Faria CD, Teixeira-Salmela LF, Silva EB, Nadeau S. Expanded timed up and go test with subjects with stroke: reliability and comparisons with matched healthy controls. Archives of Physical Medicine and Rehabilitation. 2012; 93(6):1034-038

[19] Peters DM, Fritz SL, Krotish DE. Assessing the reliability and validity of a shorter walk test compared with the 10-Meter Walk Test for measurements of gait speed in healthy, older adults. Journal of Geriatric Physical Therapy. 2013; 36(1):24-30.

[20] Adell E, Wehmhorner S, Rydwik E. The test-retest reliability of 10 meters maximal walking speed in older people living in a residential care unit. Journal of Geriatric Physical Therapy. 2013; 36(2):74-77.

[21] Amatachaya S, Naewla S, Srisim K, Arrayawichanon P Siritaratiwat $W$. Concurrent validity of the 10 -meter walk test as compared with the 6-minute walk test in patients with spinal cord injury at various levels of ability. Spinal Cord. 2014; 52(4):333-36

[22] Perry J, Burnfield JM. Gait analysis: normal and pathological function. $2^{\text {nd }}$ ed. Thorofare, N.J.: Slack Incorporated; 2010.

[23] Yamamoto S, Fuchi M, Yasui T. Change of rocker function in the gait of stroke patients using an ankle foot orthosis with an oil damper: immediate changes and the short-term effects. Prosthetics and Orthotics International. 2011; 35(4):350-59.

[24] Desloovere K, Molenaers G, Van Gestel L, Huenaerts C, Van Campenhout A, Callewaert B, et al. How can push-off be preserved during use of an ankle foot orthosis in children with hemiplegia? A prospective controlled study. Gait Posture. 2006; 24(2):142-51.

[25] Nolan KJ, Yarossi M. Preservation of the first rocker is related to increases in gait speed in individuals with hemiplegia and AFO. Clinical Biomechanics. 2011; 26(6):655-60.

[26] Fatone S, Hansen AH. Effect of ankle-foot orthosis on rollover shape in adults with hemiplegia. Journal of Rehabilitation Research \& Development. 2007; 44(1):11-20.

[27] Sobhani S, Bredeweg S, Dekker R, Kluitenberg B, van den Heuvel E, Hijmans J, et al. Rocker shoe, minimalist shoe, and standard running shoe: a comparison of running economy. Journal of Science and Medicine in Sport. 2014; 17(3):312-16. 